\title{
Connect the fragmented habitat patches for giant panda
}

\author{
Dongwei Kang ${ }^{1} \cdot$ Junqing $\mathrm{Li}^{1}$
}

Received: 24 February 2016 / Accepted: 19 April 2016/Published online: 4 May 2016

(C) Springer-Verlag Berlin Heidelberg 2016

As a globally significant iconic species for conservation, the survival status of giant panda (Ailuropoda melanoleuca) has drawn more attentions from all over the world. Through many years of protection, the numbers of wild giant panda have reached 1864 , and their habitats reached to $2,580,000$ ha (State Council Information Office of China 2015), important results of species protection have been achieved in China.

However, habitat fragmentation has always been the key factor threatening the survival of giant panda. For example, giant panda populations were divided into about 24 local populations in the early 1990s (O'Brien et al. 1994), but now, this number has increased to 33 (State Council Information Office of China 2015). To convert the present difficult situation, the State Forestry Administration plans to connect the 33 fragmented giant panda habitat patches by building ecological corridor in 3 to 5 years (State Council Information Office of China 2015). Aside from fund and technology, it is still unclear what methods should be taken in such a short time to complete so ambitions a campaign.

In fact, as early as in 1990s, the Giant panda and Habitat Protection Project, with a budget over 300,000,000 RMB and 10 years implementation period, has been carried out in China. One of the most important tasks of this project is to promote gene flow among small populations by constructing

Responsible editor: Philippe Garrigues

Junqing Li

lijunqing8100@163.com

1 The Key Laboratory for Silviculture and Conservation of Ministry of Education, Beijing Forestry University, Beijing, People's Republic of China
17 corridors among the fragmented habitats (State Forestry Administration 1993). But now, the habitat fragmentation has become more and more serious, even 20 years later after the project launched.

To facilitate the connection of fragmented giant panda habitat patches, in this article, we displayed our views and proposed some suggestions, which could provide important reference for the protection of giant panda.

(1) It is urgently needed to change the previous concept of centered on the human idea to the new concept of centered on the giant panda's habitat requirements thoroughly. In the past, people always restored the degraded habitat according to their own imagination and took the built corridor for granted. In fact, whether a certain environment could be use determined by habitat requirements of giant panda (Kang 2015), rather than human idea. Even if they use the built corridor, it would experience a long process of seeking, utilization, migration, settlement, propagation and diffusion, etc.

(2) The constraints from ecological, economical, and social (Miller and Hobbs 2007) need to be fully taken into account in corridor building. The planned corridor maybe cannot achieved in practice due to the presence of constraining factors, such as natural condition, land use right, sources of funding, public attitudes, etc. Thus, for the corridor planning, it should first pay more attention to the small populations with much higher risk of extinction and restore the 33 isolated habitat patches into several large habitat blocks based on realities by building the feasibility corridors, instead of eager to connect all small patches together.

(3) Giant panda habitat in different mountains have different characters (Hu 2001), caution should be given to the successful methods of one region's restoration to another. 
The best way is different mountains use the unified principle as a guide, that is corridor building should based on the habitat requirements of local giant pandas, but explore the different restoration standards and methods that can fit to the different regions.

(4) Priority area should be planned in corridor. For example, it should give priority for areas that nearing the suitable habitat (Hanski 2005) and/or where giant panda living, because they are more likely can be used by giant panda. Furthermore, similar to forest restoration, the remnant habitat in corridor should be paid more attention (David and Don 2003) and it should restore and expand the habitat based on and start from the edge of remnant habitat.

(5) Small-scale experiment before executing the corridor building project is required to plan, implement and evaluation, because it can help to find the defects and problems of project, and test whether the goals and measures of project need to be adjusted. Furthermore, the successful small-scale experiment is conducive to the accumulation of experience and rapid promotion.

(6) Artificial afforestation with the purpose of producing wood is not suggested. Traditional afforestation can increase the forest cover rapidly, but it usually involved planting single species, even-aged, and fast-growth individual trees with a high density, with little regard given to the function restoration, it can provide almost no habitat for giant panda and cannot fulfill the habitat requirements of them (Kang et al. 2014). Giant pandas require habitat that comprises an entire functioning ecosystem for their survival (Li and Shen 2012), rather than a simple assembly of planted trees.

(7) It is of great important to focus on different levels. For example, restoration sites carry the detailed information of project, and their performance relate to the success of corridor building directly. The landscape level can test whether the sites in the corridor can well integrated into the local landscape and play a connecting function among the different fragmented habitat patches. Thus, for the corridor building, it should make the plan on the landscape level, but start from the site level.
(8) Some restoration measures used in forest restoration also can be used in giant panda habitat restoration and corridor building, but need to be improved to adapt to the habitat requirements of giant panda. For example, it should avoid the large-scale soil preparation, building fence, engineering measures, fertilization, and using the herbicide and insecticide, etc.

(9) Corridor building is a last and heavy job, long-term perspective should establish. For example, long-term monitoring before and after executing the corridor building project are urgently needed, otherwise, no evidence can prove that the goals are achieved, although invest amounts of funds and manpower.

Acknowledgments This study was supported by the Fundamental Research Funds for the Central Universities (BLX2015-34) and the Special Research Program for Public-welfare Environmental Protection Projects (201509042).

\section{References}

Administration SF (1993) China forestry yearbook 1992. China Forestry Publishing House, Beijing

David L, Don G (2003) Rehabilitation and restoration of degraded forests. IUCN, Gland, Switzerland and Cambridge, UK and WWF, Gland, Switzerland

Hanski I (2005) The shrinking world: ecological consequences of habitat loss. International Ecology Institute, Oldendorf/Luhe

$\mathrm{Hu}$ J (2001) Research on the giant pandas. Shanghai Scientific and Technological Press, Shanghai

Kang D (2015) Research on the habitat selection of giant pandas. Dissertation, Beijing Forestry University

Kang D, Wang X, Yang H, Duan L, Li J (2014) Habitat use by giant panda in relation to man-made forest in Wanglang Nature Reserve of China. Environ Sci Pollut Res 21:13440-13445

Li J, Shen G (2012) The habitat of giant pandas. Higher Education Press, Beijing

Miller JR, Hobbs RJ (2007) Habitat restoration: do we know what we're doing? Restor Ecol 15:382-390

O’Brien SJ, Pan W, Lü Z (1994) Pandas, people and policy. Nature 369: 179-180

State Council Information Office of China (2015) Available from http:// www.scio.gov.cn/xwfbh/gbwxwfbh/fbh/Document/1395514/ 1395514.htm 